\title{
Perancangan Game Pengenalan Sampah Berbasis Android Untuk Meningkatkan Pemahaman Siswa Terhadap Jenis-Jenis Sampah
}

\author{
Ovide Decroly Wisnu Ardhi \\ Fakultas MIPA, Program Studi D3 Teknik Informatika \\ Universitas Sebelas Maret \\ Email: ovide@staff.uns.ac.id \\ Endar Suprih Wihidayat, Ika Nur Farida \\ Fakultas KIP, Pendidikan Teknik Informatika, Fakultas MIPA, Program Studi D3 Teknik Informatika \\ Universitas Sebelas Maret \\ Email: endars@staff.uns.ac.id, nurikafarida@gmail.com
}

Info Artikel

Kata Kunci :

Game, pengenalan sampah, android

Keywords :

Game, identify trash, android

Tanggal Artikel

Dikirim : 31 Januari 2019

Direvisi : 21 Februari 2019

Diterima : 4 Mei 2019

\section{Abstrak}

Meningkatkan jumlah sampah yang didaur ulang merupakan satu langkah penting menyelamatkan lingkungan. Untuk bisa meningkatkan jumlah sampah yang bisa didaur ulang bisa dilakukan dengan memilah sampah berdasarkan jenisnya. Proses memilah sampah memerlukan pengetahuan jenis-jenis sampah yang ternyata masih minim dimiliki, khususnya oleh anak umur 6-12 tahun. Penelitian ini bertujuan mengembangkan media pembelajaran persuasif untuk anak-anak, berupa game yang didalamnya secara tidak langsung mengajari anak-anak mengenali jenis-jenis sampah. Tujuan selanjutnya yaitu menguji game apakah bisa meningkatkan pemahaman anak. Untuk itu game diujikan pada 20 anak dengan rentang 612 tahun. Hasil pengujian menunjukkan nilai correlations (r) sebesar 0,864, dan (r)2 sebesar 0.746 atau $74.6 \%$, yang menunjukkan peningkatan pemahaman siswa sebesar $74.6 \%$. Nilai signifikansi yang diperoleh adalah 0.000 , dimana nilai signifikansi yang lebih kecil dari 0.005 menunjukkan bahwa game identify trash dapat meningkatkan pemahaman siswa secara signifikan.

\footnotetext{
Abstarct

Increasing the amount of recycled waste is an important step to save the environment. To be able to increase the amount of waste that can be recycled, it can be done by sorting waste by its type. The process of sorting out the garbage requires knowledge of the types of waste. In fact, that knowledge is still minimal, especially for children aged 6-12 years. This study aims to develop persuasive learning media for children, a game which indirectly teaches children to recognize the types of garbage. The next goal is to test the game whether it can improve children's understanding. The game was tested on 20 children with a range of 6-12 years. The test results show the value of correlations (r) of 0.864 , and (r) 2 of 0.746 or $74.6 \%$, which shows an increase in student understanding of $74.6 \%$. The significance value obtained is 0,000, which is smaller than 0.005, indicating that the game can significantly improve student understanding.
} 


\section{PENDAHULUAN}

Sebanyak $60 \%$ sampah perkotaan merupakan bahan organik, $14 \%$ plastik, $9 \%$ berupa kertas, $4,3 \%$ bahan metal dan $12,7 \%$ berbagai macam bentuknya mulai dari kaca kayu, dan bahan lainnya. Salah satu program yang diupayakan oleh pemerintah Indonesia adalah plastik berbayar dengan harapan Indonesia Bebas Sampah 2020 [1]. Sebagian besar sampah tersebut merupakan sampah yang bisa didaur ulang. Hal tersebut mendorong pentingnya proses memilah-milah sampah sesuai dengan jenisnya sehingga akan meningkatkan jumlah sampah yang bisa didaur ulang. Proses memilah-milah membutuhkan pengetahuan tentang jenis-jenis sampah. Melalui penelitian ini, akan dikembangkan media sebagai sarana untuk meningkatkan pengetahuan tersebut. Media ini dibuat dalam format game dengan sasaran pengguna adalah anak-anak sekolah dasar.

Game selain sebagai hiburan juga banyak digunakan sebagai media pembelajaran [2], bahkan secara khusus dirancang sebagai sarana pembelajaran [3][4]. Selain itu game yang awalnya sebagai hiburan telah banyak digunakan untuk keperluan pelatihan dan pendidikan [2]. Belum banyak penelitian yang dilakukan tentang bagaimana game digunakan dalam proseses pembelajaran. Game tidak hanya dibuat namun dapat diterima dengan baik oleh siswa, guru, dan orang tua dengan memperhatikan kurikulum dan konten [2][5]. Piirainen-Marsh dan Tainio [6] memberikan contoh pembelajaran bahasa dengan situasi pengajaran non formal, menunjukkan bahwa penggunaan game hiburan komersial itu lebih efektif dalam hal keterampilan pemecahan masalah siswa [7].

Pembelajaran game persuasif memiliki tiga pendekatan persuasif: strategi eksosentris, sebagai pendekatan yang berpusat pada permainan untuk persuasi; strategi endosentris, sebagai pendekatan pemain-sentris untuk persuasi; dan strategi gamemediated, sebagai pendekatan konteks-sentris untuk persuasi [8]. Penelitian ini sangat diperlukan, sehingga perlu dirancang sebuah games menggunakan pendekatan eksosentris, sekaligus mengukur tingkat pemahaman siswa sebelum (pretest) dan sesudah (posttest) menggunakan game. Tema game adalah pengenalan sampah dimana siswa nantinya mampu untuk mengidentifikasi jenis sampah berdasarkan jenisnya: organik, non organik, dan B3 (Bahan Berbahaya dan Beracun).

\section{METODE PENELITIAN}

Game pengenalan sampah dikembangkan menggunakan metode Heather Chandler Game Development Life Cycle dengan 4 tahapan dapat dilihat pada Gambar 1. Keempat tahapan tersebut adalah Pre-produksi, Production, Testing, dan Post Production [9][10].

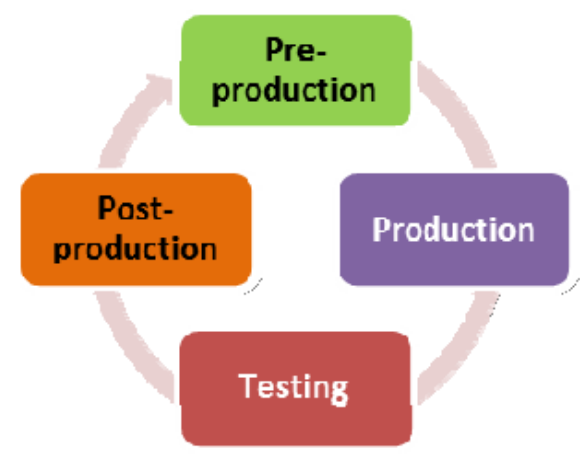

Gambar 1. Heather Chandler GDLC dengan 4 tahapan.

\subsection{Pre Production}

Tahapan pra-produksi dimulai dari mendefinisikan konsep game yang akan dibuat, menentukan gameplay, skema kontrol (playability), genre, aset dan seni yang meliputi konsep seni, karakter serta lingkungan game. Karena penelitian ini bertujuan untuk merancang sebuah game persuasif dengan pendekatan strategi eksosentris, maka perlu memperhatikan aspek-aspek seperti persuasi visual (gambar), persuasi sonik (suara), persuasi tekstual (teks), persuasi haptic (tanda-tanda haptic), persuasi naratif (cerita), persuasi audiovisual (sinematik ), dan persuasi prosedural (mekanika permainan). Persuasi eksosentris dapat dilihat pada Gambar 2. 


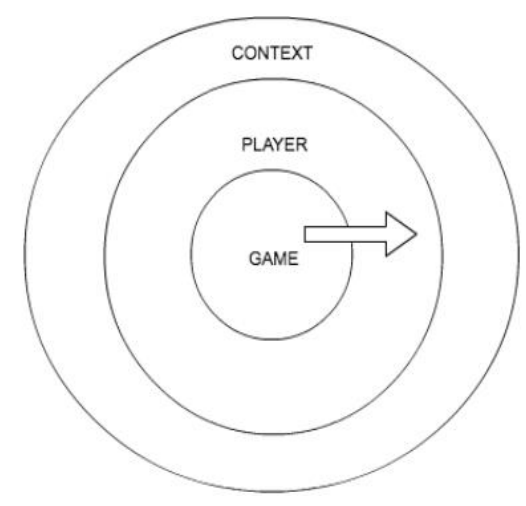

Gambar 2. Diagram eksosentris

\subsection{Production}

Tahapan ini adalah tahap yang berkaitan dengan aspek teknis dan artistik yang telah dirancang pada tahapan pra-produksi.

\subsection{Testing}

Penelitian ini dirancang untuk mengukur tingkat pemahaman siswa terhadap jenis-jenis sampah yang terdiri dari sampah organik, non-organik, dan Bahan Berbahaya dan Beracun (B3).

\subsubsection{Minimal Control (One-Group Pretest-Posttest)}

Desain penelitian yang digunakan adalah Minimal Control (One-Group Pretest-Posttest) yaitu menggunakan satu grup kontrol dengan menggunakan tes awal (pretest) dan tes akhir (posttest). Untuk mengetahui hasil perlakuan secara akurat, maka terdapat tes awal (pretest) sebelum diberi perlakuan dan tes akhir (posttest) setelah diberi perlakuan. Dengan demikian dapat dibandingkan hasil dari keduanya [11]. Desain penelitian menggunakan One-Group Pretest-Posttest dapat dilihat pada Gambar 3 .

\begin{tabular}{ccc}
\hline Pretast (tes awal) & Perlakuan & Posttest \\
\hline $0_{1}$ & $\mathrm{X}$ & $\mathrm{O}_{2}$ \\
\hline
\end{tabular}

Gambar 3. One-Group Pretest-Posttest

Keterangan, $\mathrm{O}_{1}=$ nilai pretest, $\mathrm{O}_{2}=$ nilai posttest, $\mathrm{X}=$ Pembelajaran kontekstual

\subsubsection{Populasi dan Sample}

Populasi dalam penelitian ini adalah anak Sekolah Dasar usia 6 - 12 tahun di daerah jalan Surya IV Jebres Surakarta.

\subsubsection{Uji Paired Samples T Test}

Paired Sampel t-Test adalah jenis uji statistika yang bertujuan untuk membandingkan rata-rata dua grup yang saling berpasangan. Sampel berpasangan yang dimaksud adalah sebuah sampel dengan subjek yang sama namun mengalami 2 perlakuan atau pengukuran yang berbeda, yaitu pengukuran sebelum (pretest) dan sesudah (posttest) dilakukan sebuah treatment. Uji dapat diselesaikan dengan persamaan sebagai berikut:

$$
t=\frac{\bar{x}_{1-} \bar{x}_{2}}{\sqrt{\frac{s_{1}{ }^{2}}{n_{1}}+\frac{s_{2}{ }^{2}}{n_{2}}-2 r\left(\frac{s_{1}}{n_{1}}\right)\left(\frac{s_{2}}{n_{2}}\right)}}
$$


Keterangan simbol $\overline{\boldsymbol{X}}_{1}=$ Rata-rata sampel 1, $\overline{\boldsymbol{X}}_{2}=$ Rata-rata sampel 2, $\boldsymbol{S}_{1}=$ Simpangan baku sampel 1, $\boldsymbol{S}_{2}=$ Simpangan baku sampel 2, $\boldsymbol{s}_{1}{ }^{2}=$ Varians sampel 1, $\boldsymbol{s}_{2}{ }^{2}=$ Varians sampel 2, $r=$ Korelasi antara 2 sampel.

Keterangan tahapan :

Data diolah secara statistik dengan beberapa aturan yaitu correlations, dan aturan uji T. Aturan correlations yaitu hubungan antar anggota pasangan. Sig. adalah taraf signifikan yaitu Aturannya, jika Sig $>0.05$ tidak ada hubungan antara sebelum bermanin game identify trash dan sesudahnya. Dan jika Sig $<0.05$ ada hubungan kemandirian antara sebelum bermanin game identify trash dan sesudahnya.

Jika r dikuadratkan maka menunjukkan perubahan kemampuan sesudah bermanin game identify. Aturan Uji t yaitu apabila Sig: $p<0,05$ maka ada perbedaan pada taraf sig. $5 \%$. Jika Sig: $p<0,01$ maka ada perbedaan pada taraf sig. $1 \%$. Dan jika Sig: $p>0.05$ maka tidak ada beda.

\subsection{Post-Production}

Tahapan terakhir dari pengembangan game pengenalan sampah adalah mempublikasikannya di google playstore dan diberi nama identify trash.

\section{HASIL DAN PEMBAHASAN}

Aplikasi diberi nama "Identify Trash" karena tujuan dari pembuatan aplikasi sebagai media pembelajaran untuk mengklasifikasikan jenis sampah yaitu organik, non organik, dan B3 (Bahan Berbahaya dan Beracun). Tiga pokok desain visual dalam aplikasi ini adalah karakter, obyek sampah dan environment. Karakter yang disebut player digabarkan dalam bentuk siswi Sekolah Dasar yang menggunakan baju seragam sekolah dapat dilihat pada Gambar 4.

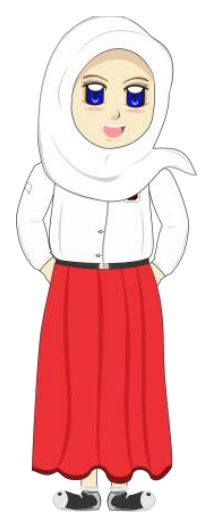

Gambar 4. Tampilan Karakter Siswi Sekolah Dasar (SD)

Obyek tempat sampah dan berbagai jenis sampah dapat dilihat pada Gambar 5 .

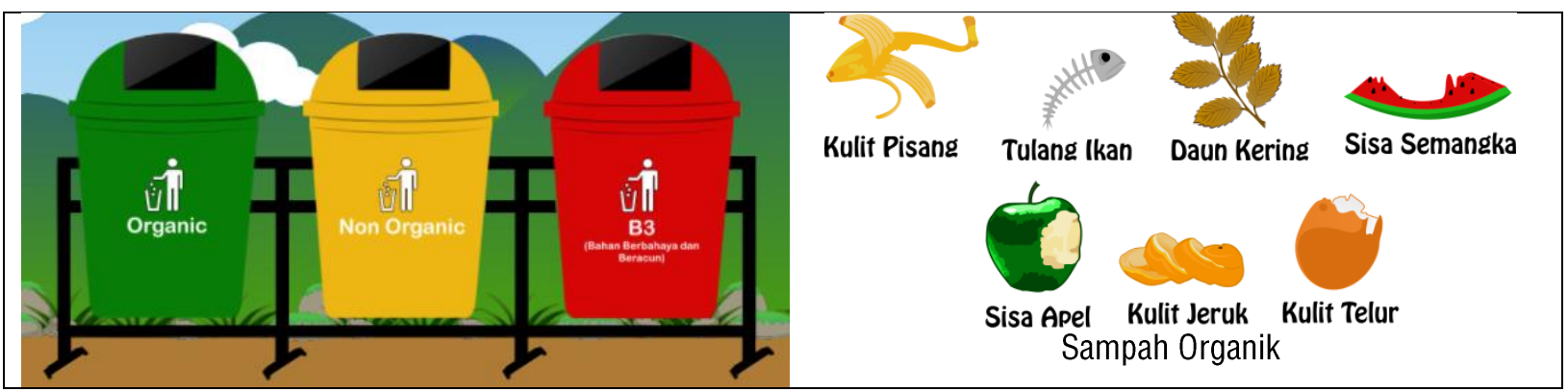




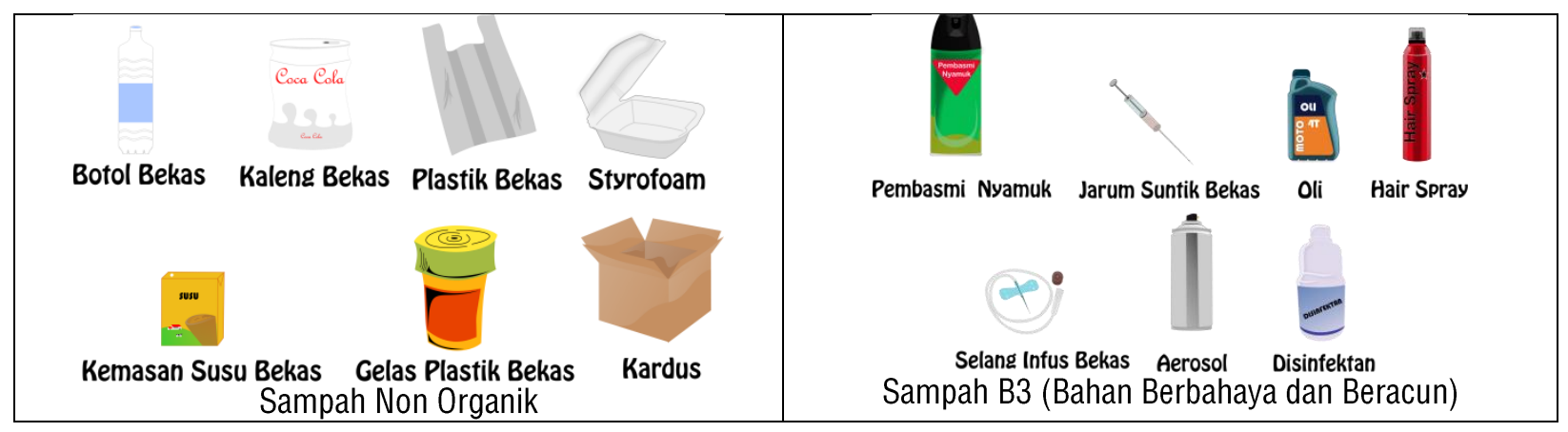

Gambar 5. Tempat sampah dan jenis sampah

Environment dalam game identify trash adalah lingkungan pedesaan dan perkotaan yang dapat dilihat pada Gambar 6.
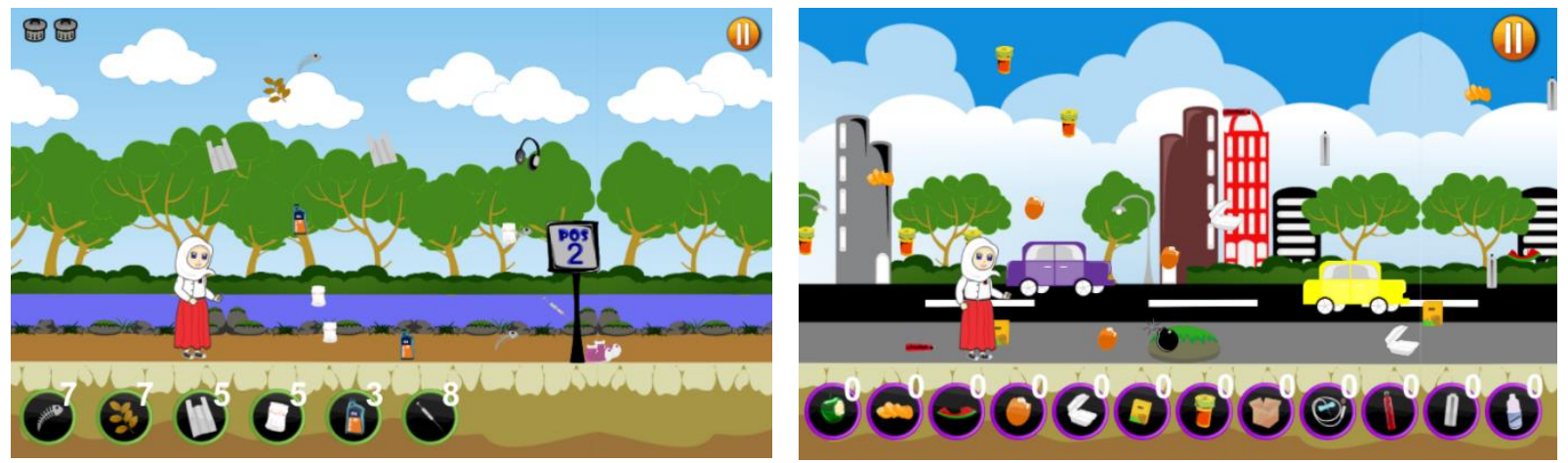

Gambar 6. Environment pedesaan dan perkotaan

Environmentyang dipilih adalah lingkungan pedesaan dan perkotaan dimana pemain akan merasakan situasi sesuai dengan kondisi masing-masing lingkungannya.

Pengujian pretest dan posttest dilakukan terhadap 20 anak dengan rentang usia 6 - 12 tahun. Anak-anak diberikan 10 pertanyaan untuk mengukur kemampuan pemahaman anak tentang klasifikasi jenis sampah organik, non organik dan B3 (Bahan Berbahaya dan Beracun) dengan skor dalam skala nilai benar dan salah. Setelah pretest dilaksanakan anak-anak diberikan treatment dengan memainkan game identify trash yang terdiri dari 3 level permainan. Setelah semua level diselesaikan dengan baik, dilakukan pengujian posttest. Data diolah dengan menggunakan Uji Paired Samples T Test dimana hasil paired samples statistics dapat dilihat pada Tabel 1, paired samples correlations dapat dilihat pada Tabel 2, dan paired samples test dapat dilihat pada Tabel 3.

Tabel 1. Paired Samples Statistics

\begin{tabular}{|c|c|c|c|c|c|}
\hline & & Mean & $\mathrm{N}$ & Std. Deviation & $\begin{array}{c}\text { Std. Error } \\
\text { Mean }\end{array}$ \\
\hline Pair 1 & $\begin{array}{l}\text { data_pretest } \\
\text { data_posttest }\end{array}$ & $\begin{array}{l}49.5000 \\
67.0000\end{array}$ & $\begin{array}{l}20 \\
20 \\
\end{array}$ & $\begin{array}{l}12.34376 \\
12.18282 \\
\end{array}$ & $\begin{array}{l}2.76015 \\
2.72416 \\
\end{array}$ \\
\hline
\end{tabular}

Data menunjukkan bahwa mean (rata-rata) penguasaan materi jenis-jenis sampah siswa pada saat pretest masih rendah dengan nilai sebesar 49,5 . Sedangkan mean setelah diberlakukan treatment dengan bermain game identify trash menunjukkan angka yang cukup tinggi dengan nilai 67,0 . Hal ini menunjukkan adanya perubahan nilai pada saat sebelum dan sesudah memainkan game identify trash.

Tabel 2. Paired Correlations

\begin{tabular}{llccc}
\hline & $\mathrm{N}$ & Correlation & $\begin{array}{c}\text { Std. Error } \\
\text { Mean }\end{array}$ \\
\hline Pair 1 & $\begin{array}{c}\text { data_pretest \& } \\
\text { data_posttest }\end{array}$ & 20 & .864 & .000 \\
\hline
\end{tabular}


Sig. bernilai 0.000 maka berdasarkan aturannya, jika Sig $<0.05$ ada hubungan kemandirian antara sebelum bermanin game identify trash dan sesudahnya karena $0.000<0.05$. Nilai correlations ( $r$ ) adalah 0,864 , jika dikuadratkan maka nilainya menjadi 0.746 atau $74.6 \%$. Peningkatan dari proses pembelajaran mengalami peningkatan $74.6 \%$.

Tabel 3. Paired Samples Test

\begin{tabular}{|c|c|c|c|c|c|c|c|c|}
\hline & \multicolumn{5}{|c|}{ Paired Differences } & \multirow[b]{3}{*}{ t } & \multirow[b]{3}{*}{$\mathrm{df}$} & \multirow[b]{3}{*}{ Sig. (2-tailed) } \\
\hline & \multirow{3}{*}{ Mean } & & \multirow{3}{*}{$\begin{array}{l}\text { Std. Error } \\
\text { Mean }\end{array}$} & \multicolumn{2}{|c|}{$95 \%$ Confidence Interval Difference } & & & \\
\hline & & \multirow[t]{2}{*}{$\begin{array}{c}\text { Std. } \\
\text { Deviation }\end{array}$} & & & & & & \\
\hline & & & & Lower & Upper & & & \\
\hline $\begin{array}{l}\text { Pair } 1 \text { data_pretest- } \\
\text { data_posttest }\end{array}$ & -17.50000 & 6.38666 & 1.42810 & -20.48905 & -14.51095 & -12.254 & 19 & .000 \\
\hline
\end{tabular}

Nilai Sig. (2-tailed) adalah 0.000, dimana Sig $<0.005$, maka HO ditolak dan H1 diterima, jadi kesimpulannya ada perbedaan antara posttest dengan pretest.

\section{KESIMPULAN}

Hasil dari penelitian ini adalah telah dirancang game identify trash dengan pendekatan eksosentris sebagai media pembelajaran pengenalan jenis-jenis sampah organil, non organik dan B3 (Bahan Berbahaya dan Beracun). Game identify trash diujikan pada 20 siswa dengan rentang usia 6 - 12 tahun dengan menggunakan Minimal Control (One-Group Pretest-Posttest). Pretest dan posttest dianalisis dengan Uji Paired Samples $T$ Test menghasilkan nilai correlations $(r)$ sebesar 0,864, jika dikuadratkan maka nilainya menjadi 0.746 atau $74.6 \%$, sehingga proses pembelajaran mengalami peningkatan $74.6 \%$. Nilai Sig. (2-tailed) adalah 0.000 , dimana $\mathrm{Sig}<0.005$, maka $\mathrm{HO}$ ditolak dan $\mathrm{H} 1$ diterima, jadi terdapat perbedaan antara posttest dengan pretest. Hasil penggunaan game identify trash sebagai media pembelajaran pengenalan sampah terbukti meningkatkan pemahaman siswa terhadap jenis sampah organik, non organik dan B3.

\section{DAFTAR PUSTAKA}

[1] Suara Pembaharuan, "Bijak Tangani Plastik: Dua Kota Indonesia Produksi 1,3 Juta Ton Sampah," Kesra. p. 20, 2018.

[2] J. Kirriemuir and A. McFarlane, "Literature Review in Games and Learning," A NESTA Futur. Res. Rep. Rep. 8. 2004., pp. 1-40, 2004.

[3] D. S. Vogel, J. A. N. Cannon-bowers, and C. A. Bowers, "Journal of Educational Computing Research2006-Vogel-229-43," vol. 34, no. 3, pp. 229-243, 2006.

[4] S. Tobias and J. D. Fletcher, "Research on using computer games for instruction," no. January 2011, 2012.

[5] R. Sandford, M. Ulicsak, and K. Facer, "Teaching with Games: using computer games in formal education," Futur. Bristol, pp. 1-39, 2006.

[6] A. Piirainen-Marsh and L. Tainio, "Collaborative game-play as a site for participation and situated learning of a second language," Scand. J. Educ. Res., vol. 53, no. 2, pp. 167-183, 2009.

[7] Y. T. C. Yang, "Building virtual cities, inspiring intelligent citizens: Digital games for developing students' problem solving and learning motivation," Comput. Educ., vol. 59, no. 2, pp. 365-377, 2012.

[8] T. De la Hera, "Persuasive Gaming: Identifying the different types of persuasion through games," Int. J. Serious Games, vol. 4, no. 1, pp. 31-39, 2017.

[9] S. Alazab, "Game Development life cycle," Unity Game Dev. Self Employ., pp. 1-28, 2015.1

[10] H. Chandler, Fundamentals Of Game Development, Revision. Sudbury, United States: Jones and Bartlett Publishers, Inc, 2011.

[11] M. Allen, "The SAGE Encyclopedia of Communication Research Methods." Thousand Oaks, California, 2017. 